\title{
Single intravitreal bevacizumab injection effects on contrast sensitivity in macular edema from branch retinal vein occlusion
}

\author{
Efeito de uma única injeção intravítrea de bevacizumabe sobre a sensibilidade \\ ao contraste no edema macular causado por oclusão de ramo venoso da retina
}

Rony Carlos Preti ${ }^{1}$, Lisa Mariel Vasquez Ramirez ${ }^{1}$, Sergio luis Gianotti Pimentel ${ }^{1}$, Augusto Alves Lopes Motta ${ }^{1}$, Cleide Guimarães Machado ${ }^{1}$, Mário Luiz Ribeiro Monteiro ${ }^{1}$, Walter YUKIHIKo TAKahash ${ }^{2}$

\begin{abstract}
Purpose: To evaluate the effect of a single intravitreal bevacizumab injection on visual acuity, contrast sensitivity and optical coherence tomography-measured central macular thickness in eyes with macular edema from branch retinal vein occlusion. Methods: Seventeen eyes of 17 patients with macular edema from unilateral branch retinal vein occlusion were treated with a single bevacizumab injection. Patients were submitted to a complete evaluation including best corrected visual acuity, contrast sensitivity and optical coherence tomography measurements before treatment and one and three months after injection. Visual acuity, contrast sensitivity and optical coherence tomography measurements were compared to baseline values.

Results: Mean visual acuity measurement improved from 0.77 logMAR at baseline to 0.613 logMAR one month after injection ( $P=0.0001)$ but worsened to 0.75 logMAR after three months. Contrast sensitivity test demonstrated significant improvement at spatial frequencies of 3, 6, 12 and 18 cycles/degree one month after injection and at the spatial frequency of 12 cycles/degree three months after treatment. Mean \pm standard deviation baseline central macular thickness (552 $\pm 150 \mu \mathrm{m})$ reduced significantly one month (322 $\pm 127 \mu \mathrm{m}, P=0.0001)$ and three months $(439 \pm 179 \mu \mathrm{m}, P=0.01)$ after treatment.
\end{abstract}

Conclusions: Bevacizumab injection improves visual acuity and contrast sensitivity and reduces central macular thickness one month after treatment. Visual acuity returns to baseline levels at the 3-month follow-up, but some beneficial effect of the treatment is still present at that time, as evidenced by optical coherence tomography-measured central macular thickness and contrast sensitivity measurements.

Keywords: Macular edema; Retinal vein occlusion; Contrast sensitivity; Optical coherence tomography; Vascular endothelial growth factor A; Angiogenesis inhibitors/ therapeutic use; Antibodies monoclonal; Visual acuity; Injections

\section{RESUMO}

Objetivo: Avaliar o efeito de uma única injeção intravitrea de bevacizumabe na função visual, sensibilidade ao contraste, em olhos com edema macular causado por oclusão de ramo venoso retiniano.

Métodos: Dezessete olhos de 17 pacientes com edema macular unilateral causado por oclusão de ramo venoso retiniano foram tratados com uma única injeção intravítrea de bevacizumabe. Pacientes previamente foram submetidos a exame ocular completo, sensibilidade ao contraste, variável de maior interesse, melhor acuidade visual corrigida e tomografia de coerência óptica e foram reavaliados no 1ำ 3 o mês de seguimento.

Resultados: $O$ teste de sensibilidade ao contraste demonstrou melhora significante nas frequências espaciais 3, 6, 12 e 18 ciclos/grau (c/g) no primeiro mês de seguimento e na frequência espacial $12 \mathrm{c} / \mathrm{g}$ após o 30 mês de tratamento. A média da acuidade visual melhorou de 0,77no pré-tratamento para0,61 logMARno 1ํㅡês deseguimento ( $P=0,0001)$, com piora ao final do 30 mês, 0,75 logMAR. A média da espessura foveal central (552 \pm 150 $\mu \mathrm{m})$ reduziu significantemente no $10(322 \pm 127 \mu \mathrm{m}, \mathrm{P}=0,0001)$ e $30(439 \pm 179 \mu \mathrm{m}, \mathrm{P}=0,01)$ mês de seguimento.

Conclusão: No edema macular causado por oclusão de ramo venoso retiniano, uma única injeção intravitrea de bevacizumabe melhora a sensibilidade ao contraste, acuidade visual e reduz a espessura foveal central após 1 mês de tratamento. Após 3 meses de seguimento, ainda é possível observar benefício com o tratamento, como foi evidenciado pela sensibilidade ao contraste e a medida da espessura foveal central à tomografia de coerência óptica.

Descritores: Edema Macular; Oclusão da veia retiniana; Sensibilidade de contraste; Tomografia de coerência óptica; Fator A de crescimento do endotélio vascular; Inibidores da angiogênese/uso terapêutico; Anticorpos monoclonais; Acuidade visual; Injeções

\section{INTRODUCTION}

Branch retinal vein occlusion (BRVO) is a common retinal vascular disorder that can lead to significant visual loss, particularly when secondary macular edema (ME) develops ${ }^{(1)}$.

Although laser photocoagulation has been the only effective evidence-based treatment for such patients, recent evidence supports the use of intravitreal pharmacotherapies as valid adjuncts or even as alternative treatments to standard laser photocoagulation ${ }^{(2)}$.

Once a BRVO develops, retinal ischemia ensues downstream from the site of occlusion. Retinal ischemia and hypoxia are the most important upregulators of vascular endothelial growth factor (VEGF) production ${ }^{(3)}$, which constitutes one of the most potent permeabilizing agents known and which has been implicated in the pathogenesis of ME of various etiologies ${ }^{(4,5)}$. Therefore, VEGF inhibition appears to be a promising treatment modality for $\mathrm{ME}^{(6)}$. In fact, recent studies have suggested a beneficial effect of intravitreous anti-VEGF agents such as bevacizumab for the reduction of ME from different etiologies, including $\mathrm{BRVO}^{(7-10)}$. Some authors reported improvement in best corrected visual acuity (BCVA) at 1, 4, 8, and 12 weeks after just one intravitreal bevacizumab (IVB) injection; however, no significant improvement was noted after 24 weeks ${ }^{(11)}$. In 2007, a study reported that ME accompanied by BRVO recurred 2.1 months after injection
Submitted for publication: March 15,2011

Accepted for publication: November 29, 2011

Study carried out at the Division of Ophthalmology, Hospital das Clínicas of the University of São Paulo Medical School - São Paulo (SP), Brazil.

Physician, Hospital das Clínicas, Faculdade de Medicina, Universidade de São Paulo - USP - São Paulo (SP), Brazil.

Physician, Setor de Retina, Hospital das Clínicas, Faculdade de Medicina, Universidade de São Paulo - USP - São Paulo (SP), Brazil.
Funding: No specific financial support was available for this study.

Disclosure of potential conflicts of interest: R.C.Preti, None; L.M.V.Ramirez, None; S.L.G.Pimentel, None; A.A.L.Motta, None; C.G.Machado, None; M.L.R.Monteiro, None; W.Y.Takahashi, None.

Correspondence address: Rony Carlos Preti. Av. Ramalho Ortigão, 269 - Apto. 54 - São Paulo (SP) 04130-010 - Brazil - Email: rypreti@hotmail.com 
intravitreal bevacizumab (IVB) injection ${ }^{(12)}$, while others reported that the effects disappeared after 6 weeks $s^{(2,10)}$. In other study, eyes were treated with three initial IVB injections of $1.25 \mathrm{mg}$ at monthly intervals. Subsequent retreatment was based on optical coherence tomography (OCT)-measured central retinal thickness ${ }^{(13)}$.

Most of the previous studies evaluating IVB injection in eyes with BRVO have based their conclusions on BCVA and central macular thickness (CMT) measurements on OCT. However, it is important to consider that the use of other vision-function tests may provide valuable additional information in order to further evaluate the effects of treatment ${ }^{(14-17)}$. Contrast sensitivity (CS) is one such test that provides a measure of the ability to see low-contrast patterns, and it has been suggested that it can provide more information on visual function than $\operatorname{BCVA}{ }^{(14,18)}$. The strong associations between CS and functional abilities provide a rationale for including CS measurements in clinical trials ${ }^{(19)}$.

It seems clear from the above-mentioned studies that recurrence of ME after initial successful treatment is very common, and many authors have suggested two to three injections over the first 5-6 months after vein occlusion ${ }^{(12,20)}$. Other authors advise repeating IVB injection every time ME is present ${ }^{(21)}$, with frequencies of up to one injection every 6 weeks $^{(22)}$ at an increased risk of complications. Therefore, despite the general belief that repeated IVB injections are needed for the treatment of ME from BRVO, there are several issues open to questioning regarding the use of IVB injection. The most important issue is that the exact duration of the effect of IVB injection in eyes with ME from BRVO is not clear, and therefore clear-cut recommendations as to the frequency of IVB use are not available. Although patients may be given multiple injections, it is important to know what to expect of the first treatment - an issue that has not been properly dealt with in previous studies - in order to reasonably support a certain therapeutic regimen. The purpose of the present study is therefore to evaluate prospectively the effect of a single IVB injection on OCT-estimated ME, BCVA and CS in patients with BRVO followed for 3 months.

\section{METHODS}

This was an interventional, prospective, consecutive study conducted between October 2008 and December 2009. The study followed the principles of the Declaration of Helsinki, approval from the Institutional Review Board Ethics Committee was obtained and all participants gave their informed consent.

The study included 17 eyes of 17 patients (10 women) with a diagnosis of ME due to unilateral BRVO confirmed by OCT, fluorescein angiography and fundus photography. Patients were included in the study independent of the size of the area of leakage and time of occurrence of BRVO. Other inclusion criteria were CMT, as determined by OCT, greater than $300 \mu \mathrm{m}$, best-corrected distance VA measurement worse than 20/40 and absence of previous treatment over the last 3 months.

BCVA measurements were performed with the Early Treatment Diabetic Retinopathy Study (ETDRS) chart (Precision Vision, Aurora, Colorado, USA). Contrast sensitivity was measured with the VCTS ${ }^{\oplus} 6500$ (Vistech Consultants Incorporation, Dayton, $\mathrm{OH}, \mathrm{USA}$ ) in photopic conditions $\left(85 \mathrm{~cd} / \mathrm{m}^{2}\right)$ that allows evaluation of 5 spatial frequencies with sinewave grating charts ranging between 1.5 and 18 cycles/ degree (cpd). The patient should view the chart monocularly from a 10-foot distance (or 3-foot distance for low vision) with the best spectacle correction in place. The test proceeded from higher to lower contrast and from lower to higher spatial frequency. At each spatial frequency, the target with the lowest contrast that was correctly identified before any preceding error was recorded as the CS for that frequency. The contrast threshold was measured from the last correct response. CS values, derived from the table provided in the Vistech manual, ranged from 3 to 260 and depended on the frequency. The CS levels in each row ranged from 0.47 to $2.23 ; 0.60$ to 2.34; 0.70 to $2.41 ; 0.70$ to 2.23 ; and 0.60 to $1.95 \log$ units for $1.5,3,6$, 12 , and 18 cycles/degree, respectively.
Patients received one single intravitreal injection $(1.25 \mu \mathrm{g} / 0.05 \mathrm{cc}$ ) of bevacizumab. VA, CS, fluorescein angiography and OCT were performed immediately prior to treatment and repeated at 1 and 3 months after injection. All injections were performed following international guidelines at operating room sterile drape, previous 5\% topical povidone $^{(23)}$, and prophylactic topical antibiotics were given for 2 days before and 3 days postinjection.

Fluorescein angiograms were obtained after injection of $5 \mathrm{~mL}$ of $10 \%$ sodium fluorescein solution into the antecubital vein. The time for the dye to first appear in the arterioles until the end of the laminar filling stage was recorded as the arterial venous filling time. The classification of BRVO was based on fluorescein angiographic criteria: ischemic lesions had 5 or more optic disc size areas of retinal non-perfusion while non-ischemic occlusions had less than 5 such lesions.

Subjects underwent ocular imaging with dilated pupils using a commercially available, Stratus OCT (Carl Zeiss Meditec, Dublin, California, USA). Quality assessment of Stratus OCT scans was evaluated by an experienced examiner. Good-quality scans had to have focused images and signal strength equal to or higher than 7 and radial scans centered on the fovea. The fast macular thickness protocol was used to obtain macular thickness measurements with the Stratus OCT. OCT measurements of the macula were generated from six $6 \mathrm{~mm} \mathrm{li-}$ near scans in a spokelike radial configuration with each line $30^{\circ}$ apart. Macular thickness parameters were automatically calculated by the software (version 4.0.1) as the distance between the inner limiting membrane and retinal pigment epithelium.

Data regarding VA and CS were converted to logMAR before analysis and calculations. The descriptive statistics included frequency and mean value \pm standard deviation (SD) for normally distributed variables and median, first quartile and third quartile for non-normally distributed variables. Analysis of histograms and the KolmogorovSmirnov test were used to evaluate the normality assumption. We used the paired t-test for comparisons of normally distributed parameters and the Wilcoxon signed-rank test for parameters that did not satisfy the normality assumption.

We calculated correlations using either Spearman's rank or Pearson's correlation coefficients. A $P$ value of less than 0.05 was considered statistically significant. The statistical analyses were performed using the software SPSS v.15.0 (SPSS Inc., Chicago, IL, USA).

\section{RESULTS}

A total of 17 intravitreal injections of bevacizumab were performed with no ocular or systemic adverse reactions noted. Seventeen patients completed the 1-month follow-up period, and 13 patients completed the 3-month follow-up period.

At baseline, none of the eyes had evidence of retinal or iris neovascularization or elevated intraocular pressure. The mean age \pm SD was $65.5 \pm 12.1$ years. The mean duration of symptoms \pm SD before treatment was $29.0 \pm 28.6$ weeks (range 2-96 weeks). The majority of the cases presented the temporal inferior branch being the site of occlusion in, 9 (53\%) of the eyes. This data differed from the study already published ${ }^{(24)}$ in which the majority of patients presented the superior branch as the main occlusion site.

The mean baseline VA of 17 affected eyes was 0.772 logMAR. After injection, 17 eyes had a 1-month follow-up visit, which demonstrated an improvement in the mean VA to logMAR 0.613, $(P=0.0001)$. Thirteen eyes had a 3-month follow-up visit; the mean baseline VA was 0.75 logMAR and after 3 months of follow-up, 0.77 logMAR ( $P=0.139)$, demonstrating no statistical significance (Figure 1).

The CS test demonstrated in photopic conditions statistical significance in all spatial frequencies of $1.5(P=0.10), 3(P=0.005)$, $6(P=0.003), 12(P=0.001)$ and 18 cycles/degree $(P=0.007)$ at 4 -week follow-up. Statistical significance was observed after 3 months of treatment in the high spatial frequency of 12 cycles/degree $(P=0.034)$, between the thirteen eyes (Table 1). 
When considering the time of BRVO, patients' results which had a disease history of less than 1 year, $8(0.47 \%)$, was $1.5(P=0.186), 3$ $(P=0.047), 6(P=0.048), 12(P=0.021)$ and 18 cycles/degree $(P=0.031)$. And patients with a history of more than 1 year, $9(0.53 \%): 1.5(P=0.012)$, $3(P=0.051), 6(P=0.023), 12(P=0.001)$ and 18 cycles/degree $(P=0.052)$. Those patients who completed 3 months of follow-up with less than 1 year of disease, $8(61.5 \%)$, exhibited $1.5(P=0.221), 3(P=0.805), 6$ $(P=0.762), 12(P=0.174)$ and 18 cycles/degree $(P=0.327)$, and patients of more than 1 year, $5(38.5 \%), 1.5(P=0.425), 3(P=0.881), 6(P=0.101)$, $12(P=0.070)$ and 18 cycles/degree $(P=0.584)$

Statistically significant reductions in CMT by OCT were demonstrated after a single bevacizumab injection at the 4-week visit. Seventeen eyes had a 4-week follow-up OCT; the mean CRT was 552.47 $\pm 150.36 \mu \mathrm{m}$ at initial presentation and $322 \pm 127 \mu \mathrm{m}$ at the 4-week visit ( $P=0.0001)$. Among the thirteen eyes at the 3 -month follow-up, the mean CMT was $570.77 \pm 159.3 \mu \mathrm{m}$ at initial presentation and 439 $\pm 179 \mu \mathrm{m}$ at the 3 -month visit $(P=0.01)$ (Figure 2).

A statistically significant negative correlation was observed at the 3-month follow-up between CMT measurements and CS at spatial frequencies of $1.5(P=0.14), 3(P=0.002), 6(P=0.001)$, and $12(P=0.002)$ cpd (Spearman's rank correlation test). A statistically significant positive correlation was observed between CMT measurements and best-corrected VA measured at 1-month $(P=0.022)$ and 3-month $(P=0.025)$ follow-up (Pearson's correlation test).

\section{DISCUSSION}

Several studies support the hypothesis that VEGF inhibition has a beneficial effect in eyes with ME secondary to BRVO, at least in the

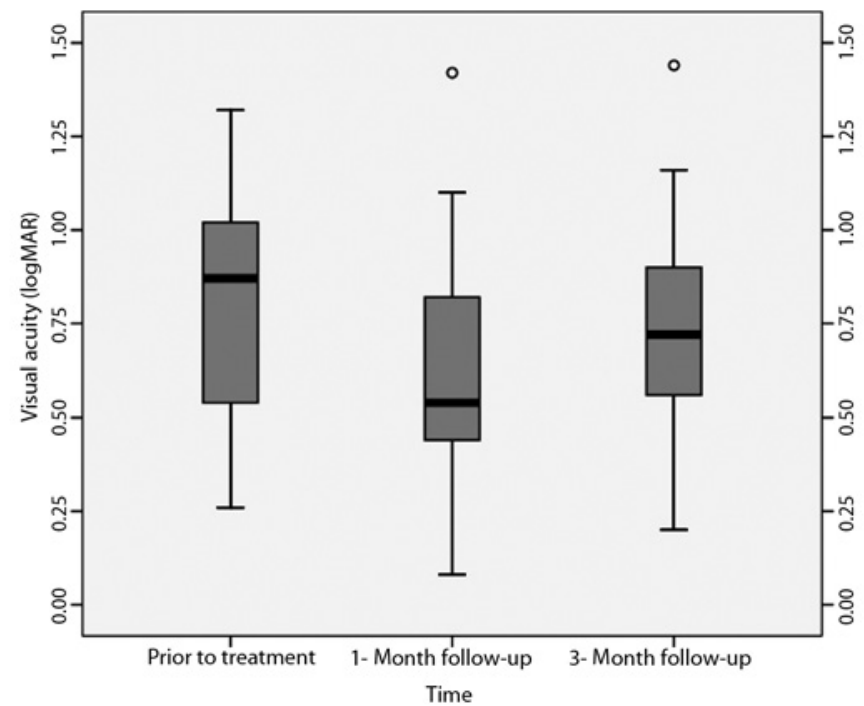

Figure 1. Box plot chart showing best corrected visual acuity before, 1 month and 3 months after intravitreal Bevacizumab injection in eyes with macular edema from branch retinal vein occlusion.

Table 1. Comparison of contrast sensitivity between baseline, 1 month and 3 months after intravitreal injection of bevacizumab in eyes with macular edema from branch retinal vein occlusion

\begin{tabular}{lccccc}
\hline $\begin{array}{l}\text { Spatial frequency } \\
\text { (cycles/degree) }\end{array}$ & $\begin{array}{c}\mathbf{1 . 5} \\
\text { (Low) }\end{array}$ & $\begin{array}{c}\mathbf{3} \\
\text { (Low) }\end{array}$ & $\begin{array}{c}\mathbf{6} \\
\text { (Middle) }\end{array}$ & $\begin{array}{c}\mathbf{1 2} \\
\text { (High) }\end{array}$ & $\begin{array}{c}\mathbf{1 8} \\
\text { (High) }\end{array}$ \\
\hline Baseline & 0.93 & 1.20 & 0.98 & 0.52 & 0.46 \\
1 month & $1.13^{*}$ & $1.46^{*}$ & $1.37^{*}$ & $1.04^{*}$ & $0.72^{*}$ \\
3 months & 0.87 & 1.16 & 1.06 & $0.80^{*}$ & 0.35 \\
\hline
\end{tabular}

${ }^{*}=P<0.05$ Wilcoxon test short term ${ }^{(8,10-12,20-22)}$. Two small prospective case series ${ }^{(8,12)}$ showed significant improvement in VA and OCT-measured CMT one month after a single IVB injection. Our data also confirm such findings because a highly statistically significant improvement was observed, in VA and OCT-measured CMT.

Nevertheless, the snellen VA test is a relatively crude index of visual function, until now it measures resolution only with high contrast targets, whereas objects in the real world exhibit varying degrees of contrast and a varying content of spatial frequencies ${ }^{(25)}$. This study measured CS and found improvement in 17 patients with ME from BRVO after a single IVB injection, between one and three months of follow up.

Considering middle (6 cycles/degree) and both high spatial frequencies (12 and 18 cycles/degree), patients with a history of less than 1 year demonstrated improvement in the middle and both high spatial frequencies when compared to patients with a history of more than 1 year that demonstrated improvement in the middle spatial frequencies and among the highs, in the 12 and 18 cycles/degrees, only in the $12^{\text {th }}$ cycle/degree. Nevertheless, in the 3 months of follow-up, no statistical significance was found. This could be perhaps due to the small number of patients or due time of reporting the disease by the patient does not match with the true onset time of BRVO, since the majority of the patients with the disease could be asymptomatic ${ }^{(26)}$.

In our study, the dose of $1.25 \mathrm{mg}$ of bevacizumab was similar to several previous studies ${ }^{(8,10-13,21,22)}$ using the same treatment modality except for that used in the study published in 2007 which used $2.5 \mathrm{mg}$ of bevacizumab with similar favorable results ${ }^{(20)}$. The favorable effect of treatment observed in our study is also in agreement with the positive results obtained by others authors which used repeated $2.0 \mathrm{mg}$ bevacizumab injections at three months interval in patients with central and hemicentral retinal vein occlusion ${ }^{(27)}$.

While it seems clear that IVB injection has a short-term beneficial effect, it is also clear from several studies that recurrence of ME is rather frequent $\mathrm{t}^{(8,11,12)}$, and very often repeated injections are necessary in patients with retinal vein occlusion. The exact duration of the beneficial effect of a single IVB injection is still unknown, and very few studies have addressed this issue in a systematic way in patients with BRVO.

Studies evaluated retrospectively the effect of IVB injection in eyes with ME from BRVO. While in all studies reduction of ME was clear after a few weeks, multiple repeated injections were used in three of these studies ${ }^{(10,12,21)}$, making it difficult to evaluate the exact duration

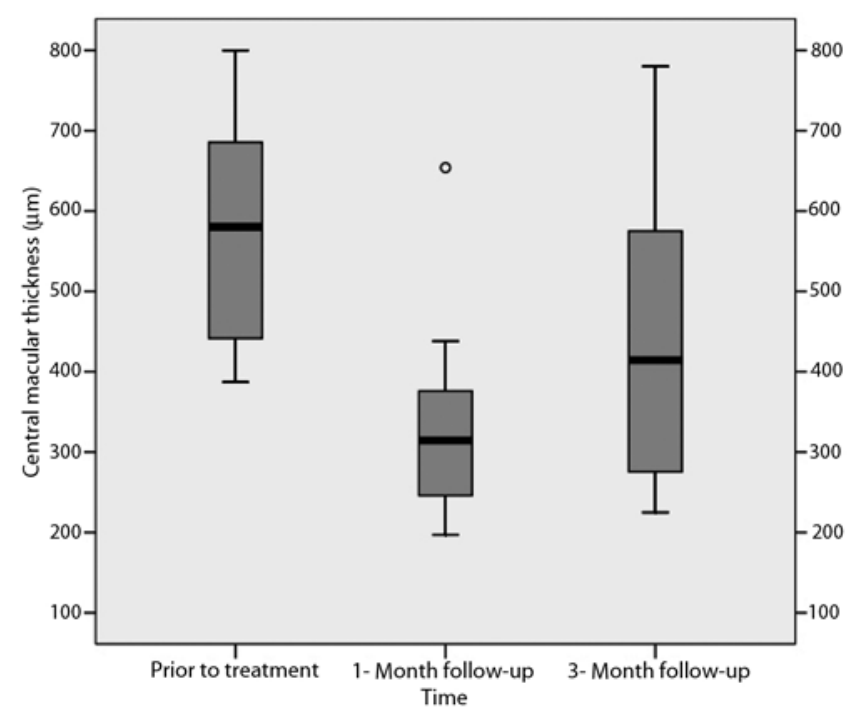

Figure 2. Central macular thickness before, 1 month and 3 months after intravitreal bevacizumab injection in eyes with macular edema from branch retinal vein occlusion. 
of the first treatment. On the other hand, the effect of a single IVB injection was evaluated retrospectively in 22 eyes with ME from BRVO and compared the effect of triamcinolone acetonide injection in 28 eyes. BCVA improved at 1, 4, 8 and 12 weeks but not at 24 weeks postinjection in the bevacizumab group ${ }^{(11)}$.

Three prospective studies evaluated the role of bevacizumab injection after BRVO. The first evaluated 22 patients with BRVO who received $2.5 \mathrm{mg}$ of IVB injection. The injections were repeated every 6 weeks when persistent or recurring ME was noted ${ }^{(20)}$. The second evaluated 12 patients with BRVO who received a single $1.25 \mathrm{mg}$ bevacizumab injection and were followed for 3 months. Visual acuity and OCT-measured CMT improved at 1 and 3 months after treatment ${ }^{(8)}$. The third evaluated the response of a single bevacizumab treatment in 7 eyes with BRVO. Improvement in VA reached a peak between 3 and 6 weeks after injection, while a decrease in VA was observed between weeks 6 and 9 . The authors suggest that using OCT examination between weeks 3 and 6 after the first treatment may be helpful in judging the appropriate time for reinjection ${ }^{(28)}$. The need of multiple repeat anti-VEGF injections has also been recently emphasized by the Branch Retinal Vein Occlusion (BRAVO) study where patients were evaluated with monthly injections of Ranibizumab for 6 months. The study enrolled 397 patients and demonstrated great beneficial in central macular thickness measurements in the treated group over a sham group ${ }^{(29)}$

Our study is important because we have evaluated in a systematic way the effect of a single IVB injection after one and three months, using not only VA and OCT-measured CMT, but also careful CS function. The reason for the continuance of CS improvement after three months of follow-up even the VA did not demonstrate it could be because some eyes with reduced central vision may surprisingly show good contrast sensitivity, especially for gratings of low spatial frequencies ${ }^{(25)}$

CS is more closely associated with tasks requiring distance judgment, night driving and mobility ${ }^{(15)}$. Patients with limitations in distinguishing contrast could have difficulties in several day-to-day situations ${ }^{(14)}$. Because it is already known that the ability of an individual to realize the details of an object is determined mainly by how that person distinguishes contrast ${ }^{(30)}$, evaluating CS is extremely important when assessing the effect of new treatment modalities. Because of this, considering both VA and CS when assessing the outcomes of clinical trials may provide a more complete picture of the effects of treatment on vision than either measure alone ${ }^{(19)}$. Our study indicated that a single IVB injection produces significant improvement in VA, CS and macular thickness measurements 4 weeks after injection, and the improvements regarding CS and macular thickness measurements last for at least 12 weeks, although VA did not differ when compared to preoperative evaluation. The optimum dosing and sequence for IVB injection in BRVO is still undetermined. While the exact number of injections necessary to maintain improved VA in cases of BRVO is unknown, our study indicates that improvement in CS and CMT is still present 3 months after a single IVB injection.

We acknowledge some shortcomings of our study, which include a relatively small number of patients, a lack of controls and a short follow-up. Nevertheless, clear evidence could be obtained that IVB injection rapidly improved VA, CS and CMT in the short-term follow-up, and the beneficial effects persisted after 3 months for CMT and CS. Multicenter clinical trials are necessary to prove the long-term effect of bevacizumab, as well as to determine the frequency of repeated injections for the treatment of ME due to BRVO.

\section{REFERENCES}

1. Argon laser photocoagulation for macular edema in branch vein occlusion. The Branch Vein Occlusion Study Group. Am J Ophthalmol. 1984;98(3):271-82.

2. Badala F. The treatment of branch retinal vein occlusion with bevacizumab. Curr Opin Ophthalmol. 2008;19(3):234-8.
3. Pe'er J, Shweiki D, Itin A, Hemo I, Gnessin H, Keshet E. Hypoxia-induced expression of vascular endothelial growth factor by retinal cells is a common factor in neovascularizing ocular diseases. Lab Invest. 1995;72(6):638-45. Comment in: Lab Invest. 1995;72(6): 615-8.

4. Adamis AP, Shima DT. The role of vascular endothelial growth factor in ocular health and disease. Retina. 2005;25(2):111-8.

5. Noma H, Funatsu H, Yamasaki M, Tsukamoto H, Mimura T, Sone T, et al. Pathogenesis of macular edema with branch retinal vein occlusion and intraocular levels of vascular endothelial growth factor and interleukin-6. Am J Ophthalmol. 2005;140(2):256-61.

6. Spandau U, Wickenhauser A, Rensch F, Jonas J. Intravitreal bevacizumab for branch retinal vein occlusion. Acta Ophthalmol Scand. 2007;85(1):118-9.

7. Iturralde D, Spaide RF, Meyerle CB, Klancnik JM, Yannuzzi LA, Fisher YL, et al. Intravitreal bevacizumab (Avastin) treatment of macular edema in central retinal vein occlusion: a short-term study. Retina. 2006;26(3):279-84.

8. Pai SA, Shetty R, Vijayan PB, Venkatasubramaniam G, Yadav NK, Shetty BK, et al. Clinical, anatomic, and electrophysiologic evaluation following intravitreal bevacizumab for macular edema in retinal vein occlusion. Am J Ophthalmol. 2007;143(4):601-6.

9. Mason JO $3^{\text {rd }}$, Albert MA Jr., Vail R. Intravitreal bevacizumab (Avastin) for refractory pseudophakic cystoid macular edema. Retina. 2006;26(3):356-7.

10. Wu L, Arevalo JF, Roca JA, Maia M, Berrocal MH, Rodriguez FJ, Evans T, Costa RA, Cardillo J; Pan-American Collaborative Retina Study Group (PACORES). Comparison of two doses of intravitreal bevacizumab (Avastin) for treatment of macular edema secondary to branch retinal vein occlusion: results from the Pan-American Collaborative Retina Study Group at 6 months of follow-up. Retina. 2008;28(2):212-9.

11. Kim JY, Park SP. Comparison between intravitreal bevacizumab and triamcinolone for macular edema secondary to branch retinal vein occlusion. Korean J Ophthalmol. 2009: 23(4):259-65. Comment in: Korean J Ophthalmol. 2010;24(3):192-3; author reply 193.

12. Rabena MD, Pieramici DJ, Castellarin AA, Avery RL. Intravitreal bevacizumab (Avastin) in the treatment of macular edema secondary to branch retinal vein occlusion. Retina. 2007;27(4):419-25.

13. Prager F, Michels S, Kriechbaum K, Georgopoulos M, Funk M, Geitzenauer W, et al. Intravitreal bevacizumab (Avastin) for macular oedema secondary to retinal vein occlusion: 12-month results of a prospective clinical trial. Br J Ophthalmol. 2009;93(4):452-6. Comment in: Br J Ophthalmol. 2010;94(3):381-3.

14. Arden GB. The importance of measuring contrast sensitivity in cases of visual disturbance. Br J Ophthalmol. 1978;62(4):198-209.

15. Rubin GS, Roche KB, Prasada-Rao P, Fried LP. Visual impairment and disability in older adults. Optom Vis Sci. 1994;71(12):750-60.

16. Rubin GS, Bandeen-Roche K, Huang GH, Muñoz B, Schein OD, Fried LP, et al. The association of multiple visual impairments with self-reported visual disability: SEE project. Invest Ophthalmol Vis Sci. 2001;42(1):64-72.

17. Elliott DB, Hurst MA, Weatherill J. Comparing clinical tests of visual function in cataract with the patient's perceived visual disability. Eye (Lond). 1990;4 (Pt 5):712-7.

18. Jin CJ, Wu DZ, Wu L. The contrast sensitivity function in low vision. Yan Ke Xue Bao. 1992; $8(1): 45-8$.

19. Monés J, Rubin GS. Contrast sensitivity as an outcome measure in patients with subfoveal choroidal neovascularisation due to age-related macular degeneration. Eye (Lond). 2005;19(11):1142-50.

20. Stahl A, Agostini H, Hansen LL, Feltgen N. Bevacizumab in retinal vein occlusion-results of a prospective case series. Graefes Arch Clin Exp Ophthalmol. 2007;245(10):1429-36.

21. Abegg M, Tappeiner C, Wolf-Schnurrbusch U, Barthelmes D, Wolf S, Fleischhauer J. Treatment of branch retinal vein occlusion induced macular edema with bevacizumab. BMC Ophthalmol. 2008;8:18.

22. Jaissle GB, Leitritz M, Gelisken F, Ziemssen F, Bartz-Schmidt KU, Szurman P. One-year results after intravitreal bevacizumab therapy for macular edema secondary to branch retinal vein occlusion. Graefes Arch Clin Exp Ophthalmol. 2009;247(1):27-33.

23. Aiello LP, Brucker AJ, Chang S, Cunningham ET Jr, D'Amico DJ, Flynn HW Jr., et al. Evolving guidelines for intravitreous injections. Retina. 2004;24(5 Suppl):S3-19. Comment in: Retina. 2005;25(7):949-50; author reply 950.

24. Rosa AA, Ortega KC, Mion D Jr, Nakashima Y. [Prevalence of arterial hypertension in branch retinal vein occlusion patients]. Arq Bras Oftalmol. 2008;71(2):162-6. Portuguese

25. Marmor MF. Contrast sensitivity versus visual acuity in retinal disease. Br J Ophthalmol. 1986;70(7):553-9.

26. Klejnberg T, Moraes Junior HV. [Ophthalmological alterations in outpatients with systemic lupus erythematosus]. Arq Bras Oftalmol. 2006;69(2):233-7. Portuguese.

27. Costa RA, Jorge R, Calucci D, Melo LA Jr, Cardillo JA, Scott IU. Intravitreal bevacizumab (avastin) for central and hemicentral retinal vein occlusions: IBeVO study. Retina. 2007; 27(2):141-9.

28. Schaal KB, Hoh AE, Scheuerle A, Schutt F, Dithmar S. [Bevacizumab for the treatment of macular edema secondary to retinal vein occlusion]. Ophthalmologe. 2007;104(4): 285-9. German

29. Campochiaro PA, Heier JS, Feiner L, Gray S, Saroj N, Rundle AC, Murahashi WY, Rubio RG; BRAVO Investigators. Ranibizumab for macular edema following branch retina vein occlusion: six-month primary end point results of a phase III study. Ophthalmology. 2010;117(6):1102-112.

30. Campbell FW, Maffei L. Contrast and spatial frequency. Sci Am. 1974;231(5):106-14. 